\section{Molecular epidemiology unmasks the tubercle bacillus: new techniques reveal new aspects of virulence}

\section{P D O Davies}

\section{Molecular methods show that TB is being transmitted with surprising efficiency}

$\mathrm{T}$ wo papers in this month's edition of Thorax show how the use of strain typing of Mycobacterium tuberculosis can reveal new aspects of tuberculosis (TB) transmission. ${ }^{12}$ The study by Ruddy et al, ${ }^{1}$ based around an outbreak of isoniazid resistant $\mathrm{TB}$ in north London, shows that a single outbreak can extend over many years and affect a broad range of individuals including medical staff. The second study by Hernández-Garduño et $a^{2}$ suggests that sputum smear negative disease can have an appreciable transmission rate. Although molecular epidemiology can unmask the problem, solutions may be more difficult to develop.

\section{OUTBREAK OF ISONIAZID RESISTANT TB}

Using IS6110 restriction fragment length polymorphism (RFLP) analysis, at the time of writing Ruddy et al had identified over 70 cases, ominously adding that, on epidemiological modelling, the peak had not yet been reached. Initial estimates by the end of December 2003 suggest that the outbreak may already have reached 132 (Dr Helen Maguire, personal communication).

This is the biggest outbreak ever identified in the UK, although not from a single point source, as was the more spectacular Leicester outbreak. ${ }^{3}$ The outbreak of isoniazid resistant TB in north London reported by Ruddy and colleagues seems to have been largely among groups of young adults of mixed ethnic backgrounds, particularly black Caribbean and white, although some were of business or professional backgrounds. Drug misuse and/or prison detention were common to many cases. Although the association between prison and TB has been well established in countries such as Russia and the $\mathrm{USA}^{4,}{ }^{4}$ this is the first prison outbreak to be documented in the UK. We have previously been quite proud of our record of keeping TB out of prisons. ${ }^{6}$ Now that record has been spoilt and may never be restored.
The Home Office has sometimes been reticent in joining the fight against $\mathrm{TB}$ but, as has been demonstrated elsewhere, prison is a continuum of the free society outside the prison walls and infections are neither confined within or without. ${ }^{78}$ Greater continuity of health care between prison and community will probably be achieved now that primary care trusts rather than the Home Office are responsible for prison health.

Drug misuse and poor adherence to treatment frequently go hand in hand, and a point made poignantly by Ruddy and colleagues is that almost a quarter of the cases had been unreliable in taking treatment, despite frequent follow up visits by specialised TB nurses. Two important methods of helping patients to comply with treatment arise from the paper but are not specifically referred to-namely, directly observed therapy (DOT) and special hospices or hostels for patients while on treatment.

New York, faced with a situation of similar proportions, invested huge amounts of money in setting up new facilities for TB treatment which included dedicated DOT workers at virtually one per patient and inpatient facilities, even using an island off the shore of New York for compulsory detention. ${ }^{9}{ }^{10}$ But the cost of controlling the epidemic was enormous, estimated at several billion dollars or approximately $\$ 20000$ per case cured. DOT workers need not be expensive if friends or former patients can be employed. One aspect of health care that we have lost in the last generation of hospital staff is patient centred user friendly TB wards not dissimilar to hospices. The enormous sums we have spent on negative pressure rooms for the treatment of drug resistant disease in our hospitals has made us forget the need to treat patients in a friendlier environment. The current recommendation for treatment of isoniazid resistant TB is for a year. ${ }^{11}$ No one would wish to stay behind a double door for so long, but a bungalow in a pleasant setting may persuade a reluctant patient to stay for some or all of the duration. They would be receiving free food and, as long as the law was not overtly broken, staff might be persuaded to turn a blind eye to some of the less medically safe habits in which patients might indulge, as long as they were present at the once daily drug round. We once had such a ward in Liverpool until it was closed by the management without discussion while I was on holiday.

In the atmosphere of politically motivated competition between hospitals, one wonders whether one hospital in (say) four in a city such as London could be persuaded to open such a ward. The presence of this type of ward may completely dispense with the need to consider compulsory detention. As the authors point out, there is no clear and rapid system for bringing extra resources to bear on such a situation. It must be hoped that the new government initiative "Getting Ahead of the

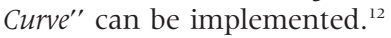

At present this ongoing outbreak represents a worrying development in the breakdown of UK public health services. Ruddy et al suggest that treatment should be supplied free of charge. If patients could be given the drugs free of charge at the clinic when they attend, the potential for breakdown in drug taking between the clinic and the patient's home would be eliminated.

Two messages come clearly from this paper. Firstly, a relatively new virulent strain of $M$ tuberculosis is being transmitted across ethnic, cultural, and financial boundaries. Secondly, those who are battling to control the infection have insufficient resources to do so.

\section{TRANSMISSION OF TB FROM SMEAR NEGATIVE PATIENTS}

The paper by Hernández-Garduño et al from Western Canada poses another worrying, if less immediate, problem. Traditionally we have regarded smear negative TB as posing almost no risk of infectivity. Historical studies have suggested that there is very little risk of cohouseholders of such a case developing disease. $^{13}$ The tendency over the last decade has been to downgrade contact tracing as cases of TB have been declining in most areas of the country with the notable exception of London, concentrating instead on contacts of smear positive cases only. ${ }^{14-16}$ Using the same IS6110 insertion sequence to identify the strain type, the authors suggest that one sixth of 791 patients identified with culture positive pulmonary and/or extrapulmonary TB received infection from a sputum smear negative case. Unlike an earlier study by Small et al from San 
Francisco ${ }^{17}$ which found that $17 \%$ of TB cases were due to smear negative transmission, Hernández-Garduño et al have included cases with extrapulmonary disease. They hypothesise that patients who appear to have extrapulmonary disease alone could be transmitting tubercle bacilli by previously undetected sputum smear negative transmission.

The methods used to ensure that apparent smear negative transmission could not have been caused by smear positive transmission appear rigorous. One theoretical confounding factor which the authors do not seem to have considered is the possibility that a smear negative patient at the time of diagnosis may have been smear positive earlier on in the disease. As the historical data suggest that $25-50 \%$ of untreated patients with pulmonary TB healed spontaneously, this remains a possibility. The finding that one sixth of the cases were due to smear negative transmission is remarkably similar to that of the earlier San Francisco study. ${ }^{17}$ The fact that half of all patients with TB have never, to their knowledge, been in contact with a case of TB (so called "casual transmission") perhaps adds some weight to this evidence. ${ }^{18}$

If this is true, what are the implications for TB control? Firstly, it means that it is going to be much harder to eliminate TB in low prevalence settings than we had hoped. Secondly, we may have to revise our contact tracing procedures to include more extensive screening of contacts of smear negative cases, particularly if these may be immunocompromised in any way. Thirdly, the implication for the provision of adequate resources for TB control in low prevalence settings is made clearly in the paper by Ruddy et al.

\section{CONCLUSIONS}

The use of molecular methods for studying the epidemiology of $\mathrm{TB}$ is proving to be a two edged sword. ${ }^{19}$ Unlike the dilemma of Pooh who found that the more he looked for Piglet in Piglet's house without finding him the more Piglet wasn't there, ${ }^{20}$ the more we look at TB with this methodology the more we find it is there or, at least, is being transmitted with surprising efficiency. The implications for resources to improve TB control are evident. Unless we can convince our political masters that this is the case, we will have to stand by and watch as things get worse.

Thorax 2004:59:273-274.

doi: $10.1136 /$ thx.2003.020081

Correspondence to: P D O Davies,

Cardiothoracic Centre, Thomas Drive, Liverpool L14 3PE; peter.davies@ctc.nhs.uk

\section{REFERENCES}

1 Ruddy MC, Davies AP, Yates MD, et al. Outbreak of isonaizid resistant tuberculosis in north London. Thorax 2004;59:279-85.

2 Hernández-Garduño E, Cook V, Kunimoto D, et al. Transmission of tuberculosis from smear negative patients: a molecular epidemiology study. Thorax 2004;59:286-90.

3 Watson JM, Moss F. TB in Leicester: out of control, or one of those things? BMJ 2001;322:1133-4.

4 Centres for Disease Control. Transmission of multidrug resistant tuberculosis among immunocompromised persons in a correctional system-New York 1991. Morbidity Mortality Weekly Rep 1992;41:507-9.
5 Yerokhin VV, Punga VV, Rybka LN. Tuberculosis in Russia and the problem of multiple drug resistance. Ann NY Acad Sci 2002;953:133-7.

6 Darbyshire JH. Tuberculosis: old reasons for a new increase? BMJ 1995;310:954-5.

7 Joint Tuberculosis Committee of the British Thoracic Society. Control and prevention of tuberculosis in the United Kingdom: code of practice 2000. Thorax 2000:55:887-901.

8 Davies P. Issues facing TB control: tuberculosis in prisons. Scottish Med J 2000;45(Suppl 1):33

9 Frieden TR, Fujiwara PJ, Washko RM, et al. Tuberculosis in New York City: turning the tide. N Engl J Med 1995;333:229-33.

10 Campion EW. Liberty and the control of tuberculosis. N Engl J Med 1999;340:385-6.

11 Joint Tuberculosis Committee of the British Thoracic Society. Chemotherapy and management of tuberculosis in the United Kingdom: recommendations 1998. Thorax 1998;53:536-48.

12 Department of Health. Getting ahead of the curve. http://www.doh.gov.uk/cmo/idstrategy/ (updated 11 August 2003, accessed 12 December 2003).

13 Subcommittee of the Joint Tuberculosis Committee of the British Thoracic Society. Control and prevention of tuberculosis in Britain: an updated code of practice. BMJ 1990;300:995-9.

14 Ansari A, Thomas I, Campbell IA. Refined tuberculosis contact tracing in a low incidence area. Respir Med 1998;92:1127-31.

15 Communicable Disease Surveillance Centre. Protecting the population from infection. http:// www.hpa.org.uk/infections/topics_az/tb/pdf/ TBpreliminaryreport_01.pdf (updated 4 August 2003, accessed 12 December 2003).

16 Behr MA, Warren SA, Salamon H, et al. Transmission of Mycobacterium tuberculosis from patients smear-negative for acid-fast bacilli. Lancet 1999;353:444-9.

17 Small PM, Hopewell PC, Singh SP, et al. The epidemiology of tuberculosis in San Francisco. A population-based study using conventional and molecular methods. N Engl J Med 1994;330:1703-9.

18 Dye C. Epidemiology. In: Davies PDO, ed. Clinical tuberculosis, 3rd ed. London: Arnold 2003:21-42.

19 Sonnengerg P, Godfrey-Faussett P. The use of DNA fingerprinting to study tuberculosis. In: Davies PDO, ed. Clinical tuberculosis, 3rd ed. London: Arnold, 2003:60-73.

20 Milne AA. The House at Pooh Corner.

health of exposure to parental smoking, ${ }^{23}$ which is understandable given the logistical difficulties of following individuals for many decades from birth. In this issue of Thorax Svanes and colleagues take a short cut and report cross-sectional results from the European Community Respiratory Health Survey (ECRHS) linking recalled information about parental smoking to respiratory symptoms, asthma, forced expiratory volumes, and BHR in up to 18688 adults aged $20-44$ years from 37 centres in 17 countries. ${ }^{4}$

For men and women overall, maternal smoking was positively associated with wheeze (OR 1.12), with a composite variable of three or more asthma symptoms (OR 1.14), but not with current asthma. Because of the large sample, 95\% confidence intervals were narrow and excluded unity despite excess risks of wheeze and asthma symptoms being low. The possibility that such weak effects may be due to 
confounding should be considered, although similar sized effects were found in never smokers. Maternal smoking was associated with a forced expiratory volume in 1 second $\left(\mathrm{FEV}_{1}\right)$ $24 \mathrm{ml}$ lower and ratio of $\mathrm{FEV}_{1}$ to forced vital capacity $\left(\mathrm{FEV}_{\mathrm{l}} / \mathrm{FVC}\right) \quad 0.5 \%$ lower, but not with differences in FVC or BHR. The effects of maternal smoking were greater in subjects whose mothers smoked in pregnancy but, as the authors acknowledge, this is an unreliable conclusion when exposure information is obtained by offspring recall. Overall, there was no effect of paternal smoking on any outcome. ${ }^{4}$

Several lines of evidence suggest that maternal smoking in pregnancy is a cause of childhood wheezing illness, especially transient early wheeze. ${ }^{56}$ However, mothers who smoke in pregnancy almost invariably smoke afterwards, so it is difficult to separate a potential role for maternal smoking on a causal pathway leading to a wheeze related phenotype from its action as an environmental trigger. The finding by Svanes et al that maternal smoking may increase wheeze in never smokers, despite adjustment for current passive smoking, supports a causal link between maternal smoking and wheezing phenotype(s).

Does an estimated $10 \%$ excess risk of wheeze matter? The prevalence of maternal smoking varied widely in the ECRHS but was over $40 \%$ in Denmark, Iceland, and the English speaking centres. ${ }^{4}$ We can estimate the population attributable risk (PAR) of adult wheeze due to maternal smoking in these latter centres to be $4-5 \%$, which is the amount of wheeze that could be prevented if maternal smoking was abolished. Public health interventions that halved the prevalence of maternal smoking in these centres would therefore prevent about $2 \%$ of wheeze in adults aged 20-44, which seems modest, even allowing for possible underestimation of main effects by this study. This figure ignores the influence of parental smoking on the smoking behaviour of offspring, ${ }^{7}$ although not all studies have found a link between smoking by parents and offspring. ${ }^{8}$

Before considering subgroup analyses, the strengths and weaknesses of the study should be considered. Strengths include precision of effect estimates from the large sample, standardisation across centres of exposures and outcomes, and the capacity to test for heterogeneity across multiple sociocultural settings. This last feature offers some safeguard that the associations in question are not confounded by unmeasured or poorly measured alternative risk factors, assuming that the confounding structure of known and unknown risk factors varies between populations. As with some other studies, ${ }^{9-11}$ reliance on offspring reports of parental "ever" smoking is a weakness because this may be subject to differential (recall bias) and non-differential (random) error, and provides no information about the intensity, duration, or timing of exposure during early life and childhood.

The authors could not test the accuracy of recalled information about parental smoking in their study. However, it seems reasonable to assume that most adults can remember whether their mother or father had smoked regularly during their childhood. This is supported by unpublished findings from the Midspan family study ${ }^{12}$ in which parents aged 45-64 reported their smoking habits in 1972-6 and adult offspring aged 30-59 answered a question about maternal smoking in 1996: "From memory, did your mother ever smoke cigarettes regularly?" The same enquiry was made about paternal smoking, both questions being similar to those in the ECRHS. In both studies nearly all participants responded positively or negatively about maternal (ECRHS 97\%, Midspan 99\%) and paternal (ECRHS 93\%, Midspan 99\%) smoking, despite being offered the opportunity of answering "don't know" (ECRHS) or "not sure" (Midspan). In the Midspan study there was good agreement between prerecorded and recalled maternal smoking $(\kappa=0.87, \mathrm{p}<0.0001)$ and paternal smoking $(\kappa=0.70, \mathrm{p}<0.0001)$.

The latter study also illustrates the consequences of concatenating prerecorded information about different intensities of current and former maternal smoking into a single binary variable-maternal ever smoking. Compared with adult offspring whose mothers were never smokers, offspring whose mothers were former smokers or current smokers of $1-14,15-24$, and $\geqslant 25$ cigarettes per day had $\mathrm{FEV}_{1}$ differences of $-44,-15,-108,-156 \mathrm{ml}$, respectively $(p<0.0001$ trend for never/current maternal smoking). ${ }^{12}$ The difference in $\mathrm{FEV}_{1}$ associated with maternal ever smoking was $-67 \mathrm{ml}(95 \% \mathrm{CI}-106$ to -28$)$ using pre-recorded exposure and $-61 \mathrm{ml}(95 \%$ CI -99 to -23 ) using recalled exposure ( $\mathrm{M} \mathrm{N}$ Upton, unpublished finding). The main limitation when using recalled exposure therefore seems to be loss of dose-response. There is also a small degree of attenuation of effect, probably from non-differential error.

The estimate by Svanes et al for the effect of maternal smoking on adult $\mathrm{FEV}_{\mathrm{l}}(-24 \mathrm{ml})$ lies within the $95 \%$ confidence interval for the Midspan estimate using recalled exposure. It seems unlikely that such a small decrement would be relevant to the risk of COPD unless the $\mathrm{FEV}_{1}$ deficit increases over time, perhaps by interacting with personal smoking. Svanes et al report that there were no significant interactions between maternal and personal smoking in their study, unlike findings in the Midspan family study where maternal and personal smoking synergised to increase airflow limitation. ${ }^{13}$ Possible reasons for differences between the studies include the older age of Midspan subjects and perhaps a stronger exposure "signal" in Midspan because of the availability of prerecorded information about the intensity of maternal smoking.

The review by Cook and Strachan published in Thorax concluded that samples of at least 2000 were needed to detect effects of parental smoking in children, judged by the absence of publication bias in studies recruiting more than 2000 subjects. ${ }^{1}$ According to this view, the study by Svanes et al should have sufficient power to detect effects of parental smoking in subgroups as large as this. However, this assumes not only that the effects of maternal smoking detected in children do not wane over time, but also that the signal-to-noise ratio of the main exposures (maternal or paternal smoking) match those in the studies of children included in the reviews. Both assumptions may be questioned, the latter because of the previously mentioned limitations around the assessment of parental smoking using offspring recall.

This may be a reason why some main effects in the subgroups in the study by Svanes et al did not reach conventional levels of statistical significance, despite large samples and similar point estimates. For example, the effect of maternal smoking on $\mathrm{FEV}_{1}$ was similar in men $(-22 \mathrm{ml})$ and women $(-24 \mathrm{ml})$, whereas $95 \%$ confidence intervals included zero in men but not women. When the main effects are relatively weak, it is not surprising that $95 \%$ confidence intervals estimated using regression (or logistic regression) include zero (or unity) when the data are divided further. There was no evidence from heterogeneity tests that the effects of maternal smoking on symptoms or lung function differed between men and women. It is a pity that the ECRHS did not record forced expiratory flows because, in children, parental smoking has greater proportional effects on forced expiratory flows than on volumes $^{16}$ and such measurements may have increased the study's power, assuming that the decrements in question persist as offspring age.

In contrast to findings for maternal smoking, there was evidence that the 
effect of paternal smoking differed between men and women, but only on the risk of wheeze (OR 1.13 for men, OR 0.95 for women, heterogeneity $p=0.033$ ). Despite claims made to the contrary, there was little evidence that paternal smoking adversely affected lung function in men in the study by Svanes et al (table 4). ${ }^{4}$ It is difficult to interpret the dose-response effect of number of parents smoking on lung function in the study, given the absence of effects of paternal smoking on lung function. Without information on the intensity of parental smoking, it is not possible to exclude the possibility that smoking intensity was higher in mothers whose partners smoked. It is also relevant that there was a similar size dose-response effect of number of parents smoking on $\mathrm{FEV}_{1} / \mathrm{FVC}$ impairment in men and women. The authors suggest that their results are consistent with age windows of particular vulnerability that differ by sex. This is an attractive hypothesis, ${ }^{6}{ }^{14}$ but the only convincing sex differences in their data were effects of paternal smoking on wheeze in men only.

Another strength of the study is the objective evidence of atopy. Maternal smoking was associated more strongly with wheeze in non-atopic $(\mathrm{OR}=1.23$ ) than in atopic $(\mathrm{OR}=1.04)$ subjects, a difference supported by heterogeneity tests. It is interesting that there appeared to be a greater effect of maternal smoking on wheeze in non-atopic subjects, without a correspondingly greater deficit in airflow limitation and without evidence of an effect of maternal smoking on BHR. It seems possible that there are a number of mechanisms underlying wheeze associated with maternal smoking. Although maternal smoking does not seem to have a large effect and impact on adult wheeze, it may perhaps be a tool to explore the pathogenesis of non-atopic asthma which is underdiagnosed ${ }^{15}$ and under-researched, ${ }^{16}$ yet has a large impact.

There is already substantial evidence that parental smoking, particularly maternal smoking, adversely affects the health of infants and children. ${ }^{16}$ There is little need for further data to justify public health efforts to reduce the exposure of offspring to passive smoking before or after birth. The study by Svanes et $a l^{4}$ adds to the evidence that parental smoking may have longstanding effects into adulthood on the respiratory health of offspring, and allows us to generalise evidence "that something is going on" from the limited studies that have so far been conducted in adults. ${ }^{2}{ }^{3}$ 9-11 13 However, current evidence is insufficient to assess the clinical significance of the different effects reported in adults or to understand how exposure to maternal and paternal smoking at different times before and after birth integrates to cause longstanding changes in lung structure and function.

Thorax 2004;59:274-276.

doi: $10.1136 /$ thx.2003.018424

Correspondence to: M N Upton, Woodlands Family Medical Centre, 106 Yarm Lane, Stockton-on-Tees, Cleveland TS18 1YE, UK; marknupton@aol.com

\section{REFERENCES}

1 Cook DG, Strachan DP. Summary of effects of parental smoking on the respiratory health of children and implications for research. Thorax 1999:54:357-66.
2 Jenkins MA, Hopper JL, Bowes G, et al. Factors in childhood as predictors of asthma in adult life. BMJ 1994;304,309:90-3.

3 Strachan DP, Butland BK, Anderson HR. Incidence and prognosis of asthma and wheezing illness from early childhood to age 33 in a national British cohort. BMJ 1996;312:1195-9.

4 Svanes C, Omenaas E, Jarvis D, et al. Parental smoking in childhood and adult obstructive lung disease: results from the European Community Respiratory Health Survey. Thorax 2004;59:295-302.

5 Stein RT, Holberg CJ, Sherrill D, et al. Influence of parental smoking on respiratory symptoms during the first decade of life: the Tucson children's respiratory study. Am J Epidemiol 1999;149:1030-7.

6 Stocks J, Dezateux C. The effect of parental smoking on lung function and development during infancy. Respirology 2003;8:266-85

7 Lieb R, Schreier A, Pfister H, et al. Maternal smoking and smoking in adolescents: a prospective community study of adolescents and their mothers. Eur Addict Res 2003:9:120-30.

8 McNeill AD, Jarvis MJ, Stapleton JA, et al. Prospective study of factors predicting uptake of smoking in adolescents. J Epidemiol Community Health 1989;43:72-8.

9 Masi MA, Hanley JA, Ernst $P$, et al. Environmental exposure to tobacco smoke and lung function in young adults. Am Rev Respir Dis 1988; 138:296-9.

10 Hu FB, Persky V, Flay BR, et al. An epidemiological study of asthma prevalence and related factors among young adults. J Asthma 1997;34:67-76.

11 Larsson ML, Frisk M, Hallström J, et al. Environmental tobacco smoke exposure during childhood is associated with increased prevalence of asthma in adults. Chest 2001;120:711-7.

12 Upton MN, Watt GCM, Davey Smith G, et al. Permanent effects of maternal smoking on offspring's lung function. Lancet 1998;352:453.

13 Upton MN, Davey Smith G, McConnachie A, et al. Maternal and personal cigarette smoking synergize to increase airflow limitation in adults. Am J Respir Crit Care Med 2004: 169:479-87.

14 Tager IB, Ngo L, Hanrahan JP. Maternal smoking during pregnancy: effects on lung function during the first 18 months of life. Am J Respir Crit Care Med 1995; 152:977-83.

15 Burney $\mathbf{P}$. The changing prevalence of asthma? Thorax 2002;57(Suppl II):ii36-9.

16 Pearce N, Pekkanen J, Beasley R. How much asthma is really attributable to atopy? Thorax 1999;54:268-72. 


\section{Role of outdoor aeroallergens in asthma exacerbations: epidemiological evidence}

\section{R W Atkinson, D P Strachan}

\section{Confounding factors complicate the interpretation of time series studies in examining the role of outdoor aeroallergens in asthma exacerbations}

D espite historically low levels, outdoor environmental pollutants such as nitrogen dioxide, sulphur dioxide, and particulate matter are thought to play a role in exacerbating asthma. Much of this evidence comes from ecological "time series" studies that use sophisticated statistical methods to examine temporal associations between daily counts of asthma attacks and daily levels of air pollution at the population level. A good example of this type of study is the multi-city European study APHEA (Air Pollution and Health: an European Approach). ${ }^{2}$ Panel studies have also investigated temporal associations between daily outdoor air pollution levels and asthma but use the symptoms, lung function and medication use of individuals as the health status indicators. The multi-city equivalent in panel design is the PEACE study (Pollution Effects in Asthmatic Children in Europe). However, it failed to find statistically significant associations between particle measures, sulphur dioxide and nitrogen dioxide and respiratory symptoms, peak expiratory flow and medication use. ${ }^{3}$

Only a relatively small number of studies have used the time series approach to investigate the health effects of aeroallergens at the population and individual levels. Some studies of air pollution have included pollens and fungal spores as potential confounders, ${ }^{4-7}$ while others have been designed specifically to investigate the health effects of aeroallergens. ${ }^{8-16}$ The conclusions from this latter group are inconsistent-some report significant effects of pollens and spores and others do not. This inconsistency may be because there is no real association or because of methodological problems associated with this type of study.

\section{METHODOLOGICAL PROBLEMS WITH TIME SERIES STUDIES Pollen distribution}

One methodological problem faced by researchers using time series designs is that the appropriate exposure-response curve for an effect of aeroallergens on asthma exacerbations is not known. Many pollen species have defined seasons, with high counts during these seasons and none for the remainder of the year. Their skewed distributions present the analyst with particular statistical challenges. One approach is to divide study days into groups defined by the percentiles of the pollen or spore distribution. At its simplest level, this approach can examine the health effects of aeroallergens by comparing days with zero aeroallergen counts with days with non-zero counts. By subdividing the study days into more groups, the method can reveal possible threshold values. For example Lewis et al ${ }^{11}$ examined the linearity of the effect of aeroallergens by dividing the daily counts of A\&E visits and admissions for asthma by tertile of aeroallergen counts plus a further group for days when counts were zero. They found stronger effects of grass pollens on days above the third tertile (when accompanied by thunderstorm activity). A similar finding was made by Salvaggio and co-workers. ${ }^{14}$ Newson et al ${ }^{17}$ found that the number of epidemics of asthma was over-represented on high pollen days (>50 grains $/ \mathrm{m}^{3}$ per day) compared with low pollen days or days with zero pollen counts. However, Dales et $a l^{8}$ assessed the linearity of the effect of pollen counts (classified as weeds, grasses and trees) on emergency visits for asthma to a children's regional hospital in Ontario and found no evidence for non-linearity. Whereas it is important to explore possible departures from a linear concentration-response relationship, individual studies quoting a specific threshold of effect should be interpreted with caution because such analyses are often "post hoc" (or data driven).

\section{Meteorological conditions}

Meteorological conditions may also contribute to the apparent inconsistencies in the results of time series studies of the health effects of aeroallergens. The weather may act as an effect modifier by interacting with aeroallergen levels. Salvaggio and colleagues $^{14}$ studied admissions for asthma in New Orleans in relation to total spore and pollen counts at three different levels of humidity. They found that the percentage of high asthma admission days increased on days with low or intermediate levels of humidity but not on days of high humidity. In a synoptic evaluation of asthma hospital admissions in New York, Jamason and coworkers $^{10}$ found that the impact of weather conditions varied according to season (greatest effect in autumn and winter), although they found no evidence of an effect of pollen on asthma admissions in any season.

Meteorological conditions may also have a significant indirect role on asthmatic subjects by permitting the clearance or build up of outdoor allergens. ${ }^{10}$ In most ecological time series studies of asthma exacerbations and environmental factors (aerobiological and air pollution) a direct effect of the weather is studied. Temperature and relative humidity are the most common measures although others also include rainfall, barometric pressure, and wind speed and direction. Low temperature ${ }^{18}$ and relative humidity ${ }^{818}$ are most commonly associated with independent effects on asthma admissions. The evidence for an effect of rainfall is mixed. ${ }^{9-13}{ }^{18}$ For instance, thunderstorms have been associated with asthma epidemics. ${ }^{17-19} 20-23$ One possible explanation is that the humidity preceding a thunderstorm, or rainfall during a thunderstorm, leads to the break up of pollen grains releasing starch granules that are then circulated (together with fungal spores if present) by the exceptional meteorological conditions. ${ }^{24}$

\section{Air pollution}

The possible role of air pollution in confounding or modifying the effects of pollen is of particular interest. A number of studies have investigated the possibility that pre-exposure to air pollution sensitises individuals to the effect of aeroallergens. ${ }^{25-29}$ These clinical studies have not been supplemented by many epidemiological studies. Lewis et $a l^{11}$ examined possible interactions between air pollution and both pollens 
and spores but failed to find evidence for a synergy between these environmental factors in causing daily asthma admissions and A\&E attendances in Derbyshire, UK.

\section{Coincident aeroallergen exposure}

Similar seasonal patterns for aeroallergen species can make it difficult to disentangle the separate health effects of individual pollens or spores. The colinearity in the statistical model prevents any one factor being identified as the causative agent and also can lead to an underestimation of the potential health effects. This is well illustrated by a recent study by Tobias et al. ${ }^{16}$ Their data showed two clearly defined peaks in the daily number of admissions for asthma that coincided with spikes of high concentrations of Poaceae and Plantago in the atmosphere. However, in one of the years studied both pollens reached concentrations above the 95th percentile (only just for Poaceae), but without a noticeable effect (by eye) on asthma admission numbers. Heavy rain during the pollen season was thought to have suppressed both the size of the pollen peaks and their duration.

\section{CONCLUSIONS}

The paper by Tobias and colleagues is important because it suggests that exposure to (grass) pollen in the atmosphere can have serious health effects for asthmatics. However, evidence from other studies has been less striking. The size of any health effect and the existence of a threshold in the pollen concentration at which this effect is triggered are not clear. The possible roles of meteorological conditions and other environmental factors in determining the nature of any health effects of pollens are not fully understood, although it seems that thunderstorms in particular are associated with striking epidemics of asthma in which aeroallergens may play a role. Further studies in other locations with different environmental situations are required to provide the variability in confounding factors and coincident exposures in order to clarify which aeroallergen species can have a detrimental effect on the health of asthmatics and under what conditions.

Thorax 2004; 59:277-278

doi: 10.1136/thx.2003.019133

\section{Authors' affiliations}

R W Atkinson, D P Strachan, St George's

Hospital Medical School, London

\section{Correspondence to: Mr R W Atkinson,}

Department of Community Health Sciences, St George's Hospital Medical School, Cranmer Terrace, London SW17 ORE, UK.

atkinson@sghms.ac.uk

\section{REFERENCES}

1 Sunyer J, Spix C, Quenel P, et al. Urban air pollution and emergency admissions for asthma in four European cities: the APHEA project. Thorax 1997:52:760-5.

2 Atkinson RW, Anderson HR, Sunyer J, et al. Acute effects of particulate air pollution on respiratory admissions-results from APHEA 2 project. Am J Respir Crit Care Med 2001;164:1860-6.

3 Roemer WH, Van Wijnen JH. Daily mortality and air pollution along busy streets in Amsterdam, 1987-1998. Epidemiology 2001; 12:649-53.

4 Anderson HR, de Leon AP, Bland JM, et al. Air pollution, pollens, and daily admissions for asthma in London 1987-92. Thorax 1998;53:842-8

5 Fauroux B, Sampil M, Quenel P, et al. Ozone: a trigger for hospital pediatric asthma emergency room visits. Pediatr Pulmonol 2000;30:41-6.

6 Garty BZ, Kosman E, Ganor E, et al. Emergency room visits of asthmatic children, relation to air pollution, weather, and airborne allergens. Ann Allergy Asthma Immunol 1998;81:563-70.

7 Jones GN, Sletten C, Mandry C, et al. Ozone level effect on respiratory illness - an investigation of emergency department visits. South Med J 1995;88:1049-56.

8 Dales RE, Cakmak S, Burnett RT, et al. Influence of ambient fungal spores on emergency visits for asthma to a regional children's hospital. Am J Respir Crit Care Med 2000;162:2087-90.

9 Hobday JD, Stewart AJ. The relationship between daily asthma attendance, weather parameters spore count and pollen count. Aust NZ J Med 1973;3:552-6

10 Jamason PF, Kalkstein LS, Gergen PJ. A synoptic evaluation of asthma hospital admissions in New York City. Am J Respir Crit Care Med 1997; 156:1781-8

11 Lewis SA, Corden JM, Forster GE, et al. Combined effects of aerobiological pollutants, chemical pollutants and meteorological conditions on asthma admissions and A\&E attendances in Derbyshire UK, 1993-96. Clin Exp Allergy 2000;30:1724-32.
12 Rosas I, McCartney HA, Payne RW, et al. Analysis of the relationships between environmental factors (aeroallergens, air pollution, and weather) and asthma emergency admissions to a hospital in Mexico City. Allergy 1998:53:394-401.

13 Rossi OVJ, Kinnula VI, Tienari J, et al. Association of severe asthma attacks with weather, pollen, and air pollutants. Thorax 1993:48:244-8.

14 Salvaggio J, Seabury J, Schoenhardt EA. New Orleans asthma. J Allergy Clin Immunol 1971:48:96-114.

15 Stieb DM, Beveridge RC, Brook JR, et al. Air pollution, aeroallergens and cardiorespiratory emergency department visits in Saint John, Canada. J Exposure Anal Environ Epidemiol 2000;10:461-77

16 Tobias A, Galan I, Banegas JR, et al. Short term effects of airborne pollen concentrations on asthma epidemic. Thorax 2003;58:708-10.

17 Newson R, Strachan D, Archibald E, et al. Acute asthma epidemics, weather and pollen in England, 1987-1994. Eur Respir J 1998;11:694-701.

18 Celenza A, Fothergill J, Kupek E, et al. Thunderstorm associated asthma: a detailed analysis of environmental factors. BM 1996;312:604-7

19 Dales RE, Cakmak S, Judek S, et al. The role of fungal spores in thunderstorm asthma. Chest 2003:123:745-50.

20 Davidson AC, Emberlin J, Cook AD, et al. A major outbreak of asthma associated with a thunderstorm: experience of accident and emergency departments and patients' characteristics. BMJ 1996:312:601-4.

21 Bauman A. Asthma associated with thunderstorms - grass pollen and the fall in temperature seem to be to blame. BMJ 1996:312:590-1.

22 Marks GB, Colquhoun JR, Girgis ST, et al Thunderstorm oufflows preceding epidemics of asthma during spring and summer. Thorax 2001;56:468-71

23 Newson R, Strachan D, Archibald E, et al Effect of thunderstorms and airborne grass pollen on the incidence of acute asthma in England, 1990-94. Thorax 1997;52:680-5.

24 Knox RB. Grass pollen, thunderstorms and asthma. Clin Exp Allergy 1993;23:354-9.

25 Jorres R, Nowak D, Magnussen H, et al. The effect of ozone exposure on allergen responsiveness in subjects with asthma or rhinitis. Am J Respir Crit Care Med 1996;153:56-64

26 Molfino NA, Wright SC, Katz l, et al. Effect of low concentrations of ozone on inhaled allergen responses in asthmatic subjects. Lancet 1991:338: 199-203.

27 Tunnicliffe WS, Burge PS, Ayres JG. Effect of domestic concentrations of nitrogen-dioxide on airway responses to inhaled allergen in asthmatic patients. Lancet 1994:344:1733-6.

28 Castellsague J, Sunyer J, Saez M, et al. Shortterm association between air pollution and emergency room visits for asthma in Barcelona. Thorax 1995; 50:1051-6.

29 Wyler C, Braun-Fahrlander C, Kunzli N, et al. Exposure to motor vehicle traffic and allergic sensitization. Epidemiology 2000;11:450-6.

D Halpin. NICE guidance for COPD. Thorax 2004;59:181-2.

Further details on the competing interests of the author of the above editorial and the COPD guidelines committee can be found on the Thorax website (http://thorax.bmijournals.com/ cgi/content/full/59/3/181/DC1). 